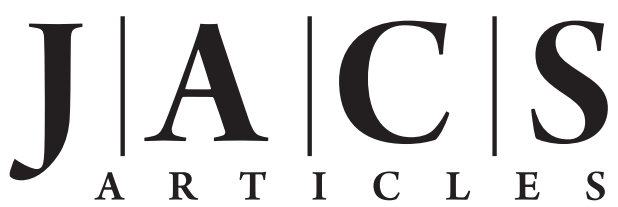

Published on Web 06/11/2009

\title{
Photoacid for Extremely Long-Lived and Reversible pH-Jumps
}

\author{
Rui M. D. Nunes, Marta Pineiro, ${ }^{*}$ and Luis G. Arnaut* \\ Chemistry Department, University of Coimbra, 3000 Coimbra, Portugal
}

Received March 18, 2009; E-mail: mpineiro@qui.uc.pt

\begin{abstract}
The ability to change the acidity of an aqueous solution within the time of a short laser pulse and use the resulting low $\mathrm{pH}$ to drive acid-catalyzed reactions in the irradiated volume opens news perspectives for the spatial and temporal control of a variety of processes. Persistent and reversible acidification of an aqueous solution is achieved with a new molecule, 1-(2-nitroethyl)-2-naphthol, that combines the fast photoacid properties of an aromatic alcohol with the slow proton transfer rates of a nitroalkane. The protons released in a few nanoseconds by pulsed laser excitation of the photoacid last for nearly one second in aqueous solutions. We show that acid-base equilibria with other species is established at the lower pHs of the irradiated volume, that the process is reversible and that it can be maintained under continuous irradiation.
\end{abstract}

\section{Introduction}

Aromatic alcohols, such as naphthols, become strong acids when they absorb light. ${ }^{1}$ Their enhanced acidity in the excited state is reasonably well predicted by the Förster equation

$$
\mathrm{p} K_{\mathrm{a}}^{*}=\mathrm{p} K_{\mathrm{a}}-\left(v_{\mathrm{HA}}-v_{\mathrm{A}-}\right) / 2.3 R T
$$

where $h v_{\mathrm{HA}\left(\mathrm{A}^{-}\right)}$is the energy of the $0-0$ electronic transition for the conjugated acid (base). In addition to a decrease in 6-8 $\mathrm{p} K_{\mathrm{a}}$ units upon electronic excitation, such photoacids also transfer very rapidly a proton to a nearby water molecule and are capable of transforming a neutral aqueous solution into an acidic one within nanoseconds.

The acidification of a solution with a photoacid and a short laser pulse can be used to perturb rapid acid-base equilibria and to initiate acid-catalyzed reactions in less than $10 \mathrm{~ns}$, which are of interest to uncover mechanisms of acid-base catalysis, ${ }^{2}$ study the initial steps of protein folding ${ }^{3}$ or phototrigger liposomal drug delivery. ${ }^{4}$ Moreover, the spatial control of $\mathrm{pH}$ in the nanoscale can be exploited for photolithography, ${ }^{5}$ and for mechanistic studies in confined (subcellular, ${ }^{6}$ nanostructured) volumes. Indeed, the features obtained by photolithography in the semiconductor industry now approach $100 \mathrm{~nm}$ and even considering the abnormally large value for the proton diffusion coefficient in water, $D=9.3 \mathrm{~nm}^{2} / \mathrm{ns}$ at $300 \mathrm{~K},{ }^{7}$ the translation distance $R_{\mathrm{t}}=\sqrt{ }(2 D t)=100 \mathrm{~nm}$ is only accessed in $550 \mathrm{~ns}$. The duration of the $\mathrm{pH}$ jump must be sufficiently longer

(1) Arnaut, L. G.; Formosinho, S. J. J. Photochem. Photobiol. A: Chem. 1993, 75, 1-20.

(2) Politi, M. J.; Fendler, J. H. J. Am. Chem. Soc. 1984, 26, 5-273.

(3) Abbruzzetti, S.; Crema, E.; Masino, L.; Vecli, A.; Viappiani, C.; Small, J. R.; Libertini, L. J.; Small, E. W. Biophys. J. 2000, 78, 405-415.

(4) Shum, P.; Kim, J.-M.; Thompson, D. H. Adv. Drug Delivery Rev. 2001, 53.

(5) Wallraff, G. M.; Hinsberg, W. D. Chem. Rev. 1999, 99, 1801-1821.

(6) Fraser, J. A.; Middlebrook, C. E.; Usher-Smith, J. A.; Schwiening, C. J.; Huang, C. L. H. J. Physiol. 2005, 563, 745-764.

(7) Agmon, N. Isr. J. Chem. 1999, 39, 493-502. than this to ensure that the nanometric features are controlled by the kinetics of the acid-catalyzed reaction with the substrate. Furthermore, it is practical to focus a laser beam to a diameter below $1 \mu \mathrm{m}$, which is comparable to the sizes of cellular organelles of most Eukaryotic animal cells. However, these potential applications require the stabilization of the $\mathrm{pH}$ drop in the irradiated volume within a nanosecond laser pulse, the maintenance of the acidity for orders of magnitude longer time scales and the absence of contamination by side products. The ideal photoacid should have a $\mathrm{p} K_{\mathrm{a}}>8$ and a low $\mathrm{p} K_{\mathrm{a}}^{*}(<2)$, deprotonate in a few nanoseconds in aqueous solutions upon electronic excitation and reversibly reprotonate very slowly. A strong, persistent and reversible photoacid would meet the specifications for the applications mentioned above.

The fast production of an acidic solution using a short laser pulse attracted much interest over the last 30 years. This was the original aim of the $\mathrm{pH}$ jump experiment, which employed naphthol derivatives. ${ }^{8}$ However, the conjugated bases of these photoacids rapidly return to the electronic ground state, where they reprotonate and neutralize the solutions in hundreds of nanoseconds. ${ }^{9}$ The bimolecular reprotonation rate increases with the concentration of the conjugated base and limits naphthols to the generation of small and short-lived $\mathrm{pH}$ jumps. Much larger $\mathrm{pH}$ jumps have been achieved with the introduction of "super" photoacids, with negative $\mathrm{p} K_{\mathrm{a}}^{*} \mathrm{~s},{ }^{10,11}$ but this did not solve the problem of the fast reprotonation of the conjugated base. Alternatively, longer-lived $\mathrm{pH}$ jumps are produced when a proton is released from a photolabile "caging" group. ${ }^{12,13}$

(8) Gutman, M.; Huppert, D. J. Biochem. Biophys. Methods 1979, 1, 919.

(9) Gutman, M.; Nachliel, E.; Gershon, E.; Giniger, R.; Pines, E. J. Am. Chem. Soc. 1983, 105, 2210-2216.

(10) Tolbert, L. M.; Haubrich, J. E. J. Am. Chem. Soc. 1994, 116, $10593-$ 10600.

(11) Tolbert, L. M.; Solntsev, K. M. Acc. Chem. Res. 2002, 35, 19-27.

(12) Bonetti, G.; Vecli, A.; Viappiani, C. Chem. Phys. Lett. 1997, 269, 268-273.

(13) Barth, A.; Corrie, J. E. T. Biophys. J. 2002, 83, 2864-2871. 
Photoactivation of such compounds initiates a series of reactions where one of the intermediates is a strong acid that deprotonates and rapidly converts into a photolysis product with low $\mathrm{p} K_{\mathrm{a}}{ }^{14}$ With such caged proton compounds, the size of the $\mathrm{pH}$ jump is limited by the $\mathrm{p} K_{\mathrm{a}}$ of the photolysis product and the irreversibility is a source of contamination.

The advances in the $\mathrm{pH}$ jump technique have been insufficient to promote it as a general tool to perturb acid-base equilibria or to induce acid-catalyzed reactions. Further progress requires a reversible photoacid capable of acidifying persistently its aqueous environment when irradiated with a single laser pulse. In this work we develop the concept of persistent and reversible photoacids using Formosinho's Interacting-State Model (ISM) ${ }^{15-17}$ and its applications to proton transfers in solution and in enzymes. ${ }^{16,18}$ ISM is employed to design the structure of a photoacid capable of very fast excited-state deprotonation and very slow ground-state reprotonation. It is shown that this can be achieved with naphthol derivatives provided that intramolecular proton transfer from an activated carbon acid is made competitive with the excited-state decay of the naphtholate. ISM calculations show that one nitro group is sufficient for this purpose if the acidic proton closes a 6-membered ring with the oxygen atom of the naphtholate. These predictions motivated the synthesis of 1-(2-nitroethyl)-2-naphthol (NO2nH). We show that aqueous solutions of this molecule remain acidic under continuous irradiation, reversibly retuning to neutrality in the dark. On-off light cycles generate acid-neutral $\mathrm{pH}$ cycles, each lasting for approximately one second. The reversibility of the system supports the operation of a molecular proton pump driven by light. Using intense and focused laser beams, it becomes possible to control acidity in the nanoscale within nanoseconds.

\section{Theoretical Design}

ISM has been described in detail in various recent publications, ${ }^{16,17,19}$ including applications to proton transfer reactions in solution ${ }^{16,20}$ and in enzymes. ${ }^{18,21}$ Briefly, the classical reaction path of ISM for the general proton transfer reaction

$$
\mathrm{B}^{-}+\mathrm{HA} \rightarrow\{\mathrm{B} \ldots \mathrm{H} \ldots \mathrm{A}\}^{-\ddagger} \rightarrow \mathrm{BH}+\mathrm{A}^{-}
$$

is a linear interpolation between the Morse curves of HA and $\mathrm{HB}$ along the reaction coordinate

$$
V_{\mathrm{cl}}(n)=(1-n) V_{\mathrm{HA}}+n V_{\mathrm{HB}}+n \Delta V^{0}
$$

where $n$ is the HB bond order and the classical reaction energy is

(14) Laimgruber, S.; Schreier, W. J.; Schrader, T.; Koller, F.; Zinth, W.; Gilch, P. Angew. Chem., Int. Ed. 2005, 44, 7901-7904.

(15) Arnaut, L. G.; Pais, A. A. C. C.; Formosinho, S. J.; Barroso, M. J. Am. Chem. Soc. 2003, 125, 5236-5246.

(16) (a) Barroso, M.; Arnaut, L. G.; Formosinho, S. J. J. Phys. Chem. A 2007, 111, 591-602. (b) http://www.ism.qui.uc.pt:8180/ism/.

(17) Arnaut, L. G.; Formosinho, S. J. Chem.-Eur. J. 2008, 14, 65786587.

(18) Barroso, M.; Arnaut, L. G.; Formosinho, S. J. J. Phys. Org. Chem. 2009, 22, 254-263.

(19) Arnaut, L. G.; Formosinho, S. J. Chem--Eur. J. 2007, 13, 80188028.

(20) Arnaut, L. G.; Formosinho, S. J.; Barroso, M. J. Mol. Struct. 2006, 786, 207-214.

(21) Barroso, M.; Arnaut, L. G.; Formosinho, S. J. J. Phys. Org. Chem. 2008, 21, 659-665.

$$
\begin{array}{r}
\Delta V^{0}=-R T\left(2.303 \mathrm{p} K_{\mathrm{HA}}+\ln \left(p_{\mathrm{A}} / q_{\mathrm{A}}\right)-2.303 \mathrm{p} K_{\mathrm{HB}}-\right. \\
\left.\operatorname{In}\left(p_{\mathrm{B} /} q_{\mathrm{B}}\right)\right)-Z_{\mathrm{HA}}+Z_{\mathrm{HB}}
\end{array}
$$

$\mathrm{p} K_{\mathrm{AH}}$ and $\mathrm{p} K_{\mathrm{BH}}$ are the thermodynamic acidity constants of $\mathrm{AH}$ and $\mathrm{BH}, p_{\mathrm{A}}\left(p_{\mathrm{B}}\right)$ is the number of equivalent protons in $\mathrm{AH}$ $(\mathrm{BH}), q_{\mathrm{A}}\left(q_{\mathrm{B}}\right)$ is the number of equivalent basic sites in $\mathrm{AH}$ $(\mathrm{BH})$, and $Z_{\mathrm{AH}}\left(Z_{\mathrm{BH}}\right)$ is the zero-point energy of the $\mathrm{AH}(\mathrm{BH})$ bond. The presence of hydrogen-bonded intermediates is included in this reaction path using the Lippincott-Schroeder potential. $^{22}$ Zero-point energies are added to the classical reaction coordinate of ISM and the resulting vibrationally adiabatic path is employed to calculate rate constants using the semiclassical transition state theory. Intramolecular proton transfers are treated in the same way, except that the entropy lost in attaining the six-membered ring may be taken from that of cyclohexane, $\Delta^{\ddagger} S=-18.8 \mathrm{cal} \mathrm{mol}^{-1} \mathrm{~K}^{-1},{ }^{23}$ and included in the pre-exponential factor. Details are given in the Supporting Information. The calculations were run in the freely available Internet application, ${ }^{16 \mathrm{~b}}$ uploading the input files presented in the Supporting Information. The output files are also presented in the Supporting Information.

Figure 1 presents the rates of the proton transfer cycle calculated with ISM based on known $\mathrm{p} K_{\mathrm{a}}$ values of analogous compounds, $\mathrm{p} K_{\mathrm{a}}(2$-naphthol $)=9.45^{10}$ and $\mathrm{p} K_{\mathrm{a}}$ (2-nitro-ethyl)benzene $=8.78$ in water and 9.82 in $50 \% \mathrm{MeOH} / \mathrm{H}_{2} \mathrm{O},{ }^{24}$ respectively. ISM predicts that intramolecular quenching of the electronically excited naphtholate ion by an acidic proton of a nitroalkane moiety is competitive with its nanosecond lifetime. For example, the anion derived from 1-propyl-2-naphthol has an excited state decay with a major component $\mathrm{ca} .5 \times 10^{7}$ $\mathrm{s}^{-1},{ }^{25}$ whereas the calculated intramolecular proton transfer rate constant from the acidic carbon to $\mathrm{RO}^{-}$is $k_{\mathrm{ipt}}=2.6 \times 10^{8} \mathrm{~s}^{-1}$. Thus, we expect that $80 \%$ of the naphtholate fluorescence is quenched by nonadiabatic intramolecular proton transfer to yield a ground-state carbanion located at the $\alpha$ position to the nitro group. This carbanion is trapped in a deep potential well, with a barrier of $7 \mathrm{kcal} / \mathrm{mol}$ preventing its protonation by the oxonium ion and a barrier of $14 \mathrm{kcal} / \mathrm{mol}$ in the way of the ground-state intramolecular proton transfer from the naphthol moiety.

The intramolecular proton transfer neutralizes the naphtholate but generates a carbanion next to a nitro group, which is recognized as the best carbanion-stabilizing group in organic chemistry. ${ }^{26}$ ISM calculated rate constants for the protonation of this carbanion and for the deprotonation of the corresponding nitroalkane are $k_{\mathrm{p}}=5 \times 10^{4}$ and $k_{\mathrm{d}}=8 \times 10^{-7} \mathrm{M}^{-1} \mathrm{~s}^{-1}$, respectively, but the deprotonation in water is more conveniently expressed as a first-order rate with $k_{\mathrm{d}}\left[\mathrm{H}_{2} \mathrm{O}\right] \approx 4 \times 10^{-5} \mathrm{~s}^{-1}$. The protonation of this carbanion is $10^{6}$ times slower than that of ground-state 2-naphtholate, which is controlled by diffusion, and is expected to lead to $\mathrm{pH}$ jumps lasting one million times longer than those produced by naphthols.

The quantitative treatment of the carbanion reprotonation kinetics in a $\mathrm{pH}$ jump experiment must take into consideration that the return of the solution to neutrality is governed by the re-establishment of the equilibrium

(22) Barroso, M.; Arnaut, L. G.; Formosinho, S. J. ChemPhysChem 2005, 6, 363-371.

(23) Lowry, T. H.; Richardson, K. S., Mechanism and Theory in Organic Chemistry, 3rd ed.; Harper \& Row Publishers: New York, 1987.

(24) Bordwell, F. G.; Bartmess, J. E. J. Org. Chem. 1978, 43, 3101-3107.

(25) Tolbert, L. M.; Harvey, L. C.; Lum, R. C. J. Phys. Chem. 1993, 97, 13335-13340.

(26) Backstrom, N.; Burton, N. A.; Turega, S.; Watt, C. I. F. J. Phys. Org. Chem. 2008, 21, 603-613. 


$$
\mathrm{H}^{+}+\mathrm{NO} 2 \mathrm{n}^{-} \rightleftharpoons \mathrm{NO} 2 \mathrm{nH}
$$

Under typical experimental conditions, $[\mathrm{NO} 2 \mathrm{nH}]_{0} \approx 10^{-4} \mathrm{M}$, $\mathrm{p} K_{\mathrm{a}} \approx 9, \mathrm{pH} 7$, the relaxation time calculated with (6) is 2 seconds. The intramolecular carbanion protonation channel shown in Figure 1 also contributes to the relaxation time at millimolar photoacid concentrations, reducing it to $c a .1 \mathrm{~s}$.

$$
\tau=\frac{1}{k_{\mathrm{p}}\left(\left[\mathrm{NO} 2 \mathrm{n}^{-}\right]_{\mathrm{eq}}+\left[\mathrm{H}^{+}\right]_{\mathrm{eq}}\right)+k_{\mathrm{d}}\left[\mathrm{H}_{2} \mathrm{O}\right]}
$$

In summary, the ISM design of a persistent and reversible photoacid indicates that 1-(2-nitroethyl)-2-naphthol should deprotonate in the excited state within a nanosecond laser pulse to yield a carbanion competitively with a ground-state naphtholate, and that the carbanion may relax in one second back to neutrality.

\section{Experimental Procedures}

Materials. The reactants 2-hydroxynaphthalene-1-carbadehyde, nitromethane, $L$-proline, $\mathrm{NaBH}_{4}$ and $o$-nitrobenzaldehyde were purchased from Aldrich. ${ }^{1} \mathrm{H}$ and ${ }^{13} \mathrm{C}$ NMR spectra were recorded in $\mathrm{CDCl}_{3}$ solutions on Bruker Avance III de $400 \mathrm{MHz}$ spectrometer.

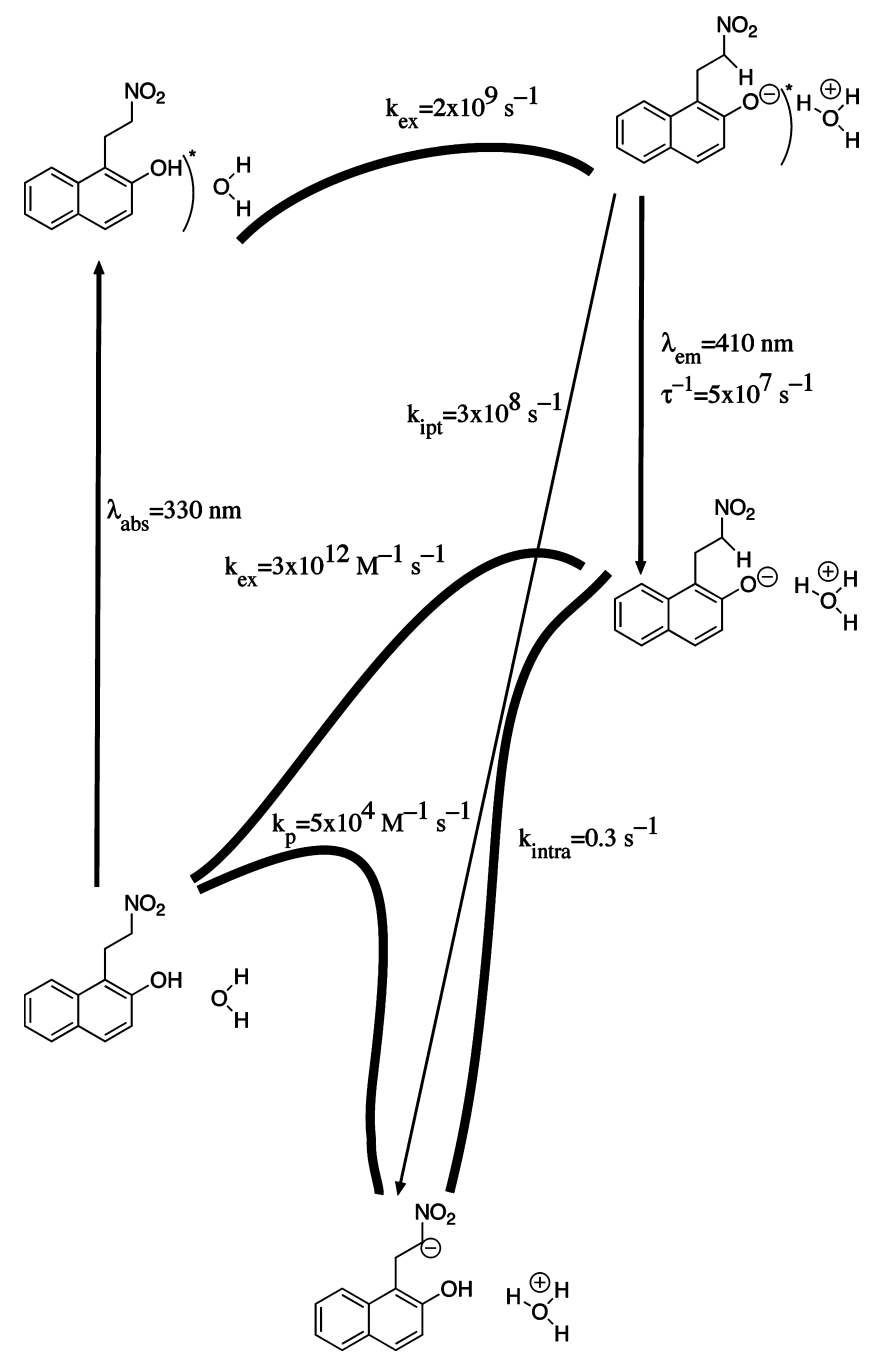

Figure 1. Energy landscape of $\mathrm{NO} 2 \mathrm{nH}$ according to ISM. It was assumed that $\mathrm{p} K_{\mathrm{a}}^{*}($ naphthol $)=2, \mathrm{p} K_{\mathrm{a}}($ naphthol $)=9.4$ and $\mathrm{p} K_{\mathrm{a}}($ nitroalkane $)=9$ [see Supporting Information for the details of ISM calculations].
Potassium ferrioxalate actinometry was made according to standard procedures. $^{27,28}$

1-(2-Nitro-vinyl)-naphthalen-2-ol. 2-Hydroxynaphthalene-1carbaldehyde (500 mg, $5.8 \mathrm{mmol})$, nitromethane $(0.31 \mathrm{~mL}, 5.8$ $\mathrm{mmol}$ ) and $L$-proline $(125 \mathrm{mg}, 25 \%, \mathrm{w} / \mathrm{w})$ were dissolved in 20 $\mathrm{mL}$ of methanol and heated at $50{ }^{\circ} \mathrm{C}$. The reaction was followed by TLC until the reagents were undetectable. The reaction mixture was cooled to room temperature and the solvent evaporated. The reaction crude was dissolved in a mixture ether:dichloromethane $(1: 5, \mathrm{v} / \mathrm{v})$ and warmed at $40{ }^{\circ} \mathrm{C}$ in a water bath until complete solubilization. Cooling to room temperature, 1-(2-nitro-vinyl)naphthalen-2-ol precipitates as a solid in $17 \%$ yield.

1-(2-Nitro-ethyl)-naphthalen-2-ol (NO2nH). 1-(2-Nitro-vinyl)naphthalen-2-ol (250 mg, $1.2 \mathrm{mmol})$ was dissolved in $10 \mathrm{~mL}$ of a mixture of THF/methanol $(1: 10, \mathrm{v} / \mathrm{v})$. Sodium borohydride was added, in portions to the stirring solution until the reaction mixture turned colorless. After quenched with water, the reaction mixture was extracted using dichloromethane $/ \mathrm{NaCl}(\mathrm{aq})$ at low temperature. After evaporation the dry product was obtained in $71 \%$ yield. In this work we employ the more trivial name 1-(2-nitroethyl)-2naphthol for this molecule. ${ }^{1} \mathrm{H}$ NMR $\left(400 \mathrm{MHz}, \mathrm{CDCl}_{3}\right) \delta$, ppm: $7.89(\mathrm{~d}, 1 \mathrm{H}, J=8.6 \mathrm{~Hz}), 7.79(\mathrm{~d}, 1 \mathrm{H}, J=8.1 \mathrm{~Hz}), 7.70(\mathrm{~d}, 1 \mathrm{H}, J=$ $8.8 \mathrm{~Hz}), 7.54(\mathrm{t}, 1 \mathrm{H}, J=7.6 \mathrm{~Hz}), 7.37(\mathrm{t}, 1 \mathrm{H}, J=7.5 \mathrm{~Hz}), 7.04(\mathrm{~d}$, $1 \mathrm{H}, J=8.8 \mathrm{~Hz}), 4.67(\mathrm{t}, 1 \mathrm{H}, J=7.6 \mathrm{~Hz}), 3.81(\mathrm{t}, 1 \mathrm{H}, J=7.6 \mathrm{~Hz})$. ${ }^{13} \mathrm{C}$ NMR (400 MHz, $\mathrm{CDCl}_{3}$ ) $\delta$, ppm: 151.4, 132.9, 129.5, 129.4, 129.0, 127.4, 123.6, 121.8, 117.6, 113.6, 74.1, 19.7. MS (MALDITOF), $m / z: 217\left(\mathrm{M}^{+}\right)$.

Methods. Absorption and luminescence spectra were recorded with Shimadzu UV-2100 and SPEX Fluoromax 3.22 spectrophotometers, respectively. Fluorescence lifetimes were measured with a previously described home-built time-correlated single-photon counting (SPC) apparatus using IBH nanoLEDs $(281 \mathrm{~nm})$ as excitation sources, Philips XP2020Q photomultiplier with excitation and emission wavelengths selected with Jobin-Ivon H20 monochromators, and a Canberra Instruments time-to-amplitude converter and multichannel analyzer. ${ }^{29}$ Transient triplet-triplet absorption was obtained with an Applied Photophysics LKS.60 flash photolysis spectrometer with the R928 photomultiplier from Hamamatsu for detection and the HP Infinium $(500 \mathrm{MHz}, 1 \mathrm{GSa} / \mathrm{s})$ or Tektronix DPO 7254 (2.5 GHz, $40 \mathrm{GSa} / \mathrm{s}$ ) oscilloscopes. Excitation employed the fourth harmonic of a Spectra-Physics Quanta Ray GCR 130 Nd:YAG laser (5-6 ns pulse width). The energy per pulse was typically below $5 \mathrm{~mJ}$ at $266 \mathrm{~nm}$.

\section{Results and Discussion}

The synthesis of 1-(2-nitroethyl)-2-naphthol, $\mathrm{NO} 2 \mathrm{nH}$, was achieved through a Henry reaction using $L$-proline as catalyst, ${ }^{30}$ and subsequent reduction with methanolic sodium borohydride. ${ }^{31}$ The negative influence of the hydroxyl group at the ortho position of the aldehyde in the Henry reaction was avoided using 2-benzyloxy-naphthalene-1-carbaldehyde. In fact, the corresponding condensation product, 2-benzyloxy-1-(2-nitrovinyl)-naphthalene, was obtained in $63 \%$ yield. The use of the aldehyde with the unprotected hydroxyl group in the condensation opens new routes for other reduction strategies for the carbon-carbon double bond, and gives us access to the desired product, although compromising the overall yield. Figure 2 shows the NMR spectrum of the molecule, with the triplet

(27) Hatchard, C. G.; Parker, C. A. Proc. R. Soc. 1956, A235, 518.

(28) Arnaut, L. G.; Formosinho, S. J.; Burrows, H. D. Chemical Kinetics; Elsevier: Amsterdam, 2007; p 549.

(29) Melo, J. S.; Fernandes, P. F. J. Mol. Sruct. 2001, 69, 565.

(30) Kürti, L.; Czakó, B. Strategic applications of named reactions in organic synthesis; Elsevier Academic Press: London, 2005.

(31) Varma, R. S.; Kabalka, G. W. Synth. Commun. 1985, 15, 151. 


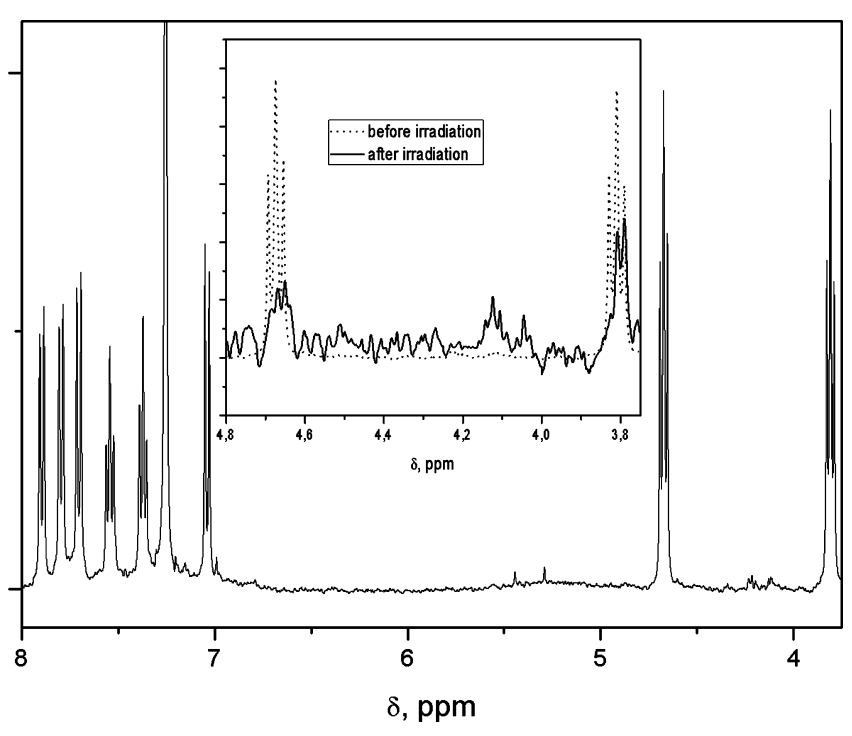

Figure 2. NMR spectra of $\mathrm{NO} 2 \mathrm{nH}$. (Inset) Alkyl region of the NMR spectra before and after $1 \mathrm{~min}$ irradiation with a low-pressure halogen lamp at $254 \mathrm{~nm}$.

corresponding to benzylic protons centered at 3.80, and the triplet at 4.67 assigned to the protons of the carbon $\alpha$ to the nitro group.

Figure $3 \mathrm{~A}$ presents the absorption spectra of $\mathrm{NO} 2 \mathrm{nH}$ at different $\mathrm{pH}$ values. $\mathrm{NO} 2 \mathrm{nH}$ is mostly present in the neutral form at $\mathrm{pH} \leq 7$. Two ionization constants were measured, with $\mathrm{p} K_{\mathrm{a}} \mathrm{s} 9.7$ and 11.6, corresponding to the loss of one and two protons, respectively, in $2 \% \mathrm{MeOH} / \mathrm{H}_{2} \mathrm{O}$. In view of the expected similarity between the $\mathrm{p} K_{\mathrm{a}} \mathrm{s}$ of naphthol and 2-phenyl1-nitroethane, the lower $\mathrm{p} K_{\mathrm{a}}$ corresponds to an anion exchanging a proton between the naptholate and the carbanion. The second ionization of this species requires a high $\mathrm{pH}$. Figure $3 \mathrm{~B}$ shows that the ratio of fluorescence intensities $* \mathrm{RO}^{-} / * \mathrm{ROH}$ of $\mathrm{NO} 2 \mathrm{nH}$ at $\mathrm{pH} 7.2$ is only 0.75 , much lower than the value of 2 measured for 1-propyl-2-naphthol. ${ }^{25}$ Assuming that the radiative and nonradiative decay rates of 1-propyl-2-naphthol and $\mathrm{NO} 2 \mathrm{nH}$ are identical, and that the decay rates in the corresponding anions differ from each other only because of the presence of the nonadiabatic intramolecular proton transfer rate constant $\left(k_{\mathrm{ipt}}\right)$ in $\mathrm{NO} 2 \mathrm{nH}$, we can write

$$
\frac{k_{\mathrm{F}}^{1}+k_{\mathrm{nr}}^{1}+k_{\mathrm{ipt}}}{k_{\mathrm{F}}^{1}+k_{\mathrm{nr}}^{1}}=\frac{2}{0.75}
$$

and conclude that $63 \%$ of the $* \mathrm{RO}^{-}$fluorescence quenching is due to the acidic proton of the nitroalkane moiety.

The enhanced quenching of $* \mathrm{RO}^{-}$fluorescence in $\mathrm{NO} 2 \mathrm{nH}$ versus 1-propyl-2-naphthol, analyzed above, indicates that the efficiency of intramolecular proton transfer is $\phi_{\mathrm{H}^{+}} \approx 0.63$. The proton comes from the acidic carbon of the nitroalkane moiety, and this efficiency is also the efficiency of carbanion formation. In order to obtain the quantum yield of carbanion formation, we also need to know the $* \mathrm{RO}^{-}$formation quantum yield in $\mathrm{NO} 2 \mathrm{nH}$. At pH 11.9 (only anionic species present) $* \mathrm{RO}^{-}$must be formed with a unit quantum yield. As shown in Figure 3B, the emission intensity of the $* \mathrm{RO}^{-}$band at $420 \mathrm{~nm}$ decreases by a factor of 2.1 as the $\mathrm{pH}$ decreases from 11.9 to 7.2 (only neutral species). At $\mathrm{pH} 7.2 * \mathrm{RO}^{-}$is formed via $\mathrm{NO} 2 \mathrm{nH}$ excitation and deprotonation, and we can assign its fluorescence intensity decrease to the formation of a smaller quantity of $* \mathrm{RO}^{-}$
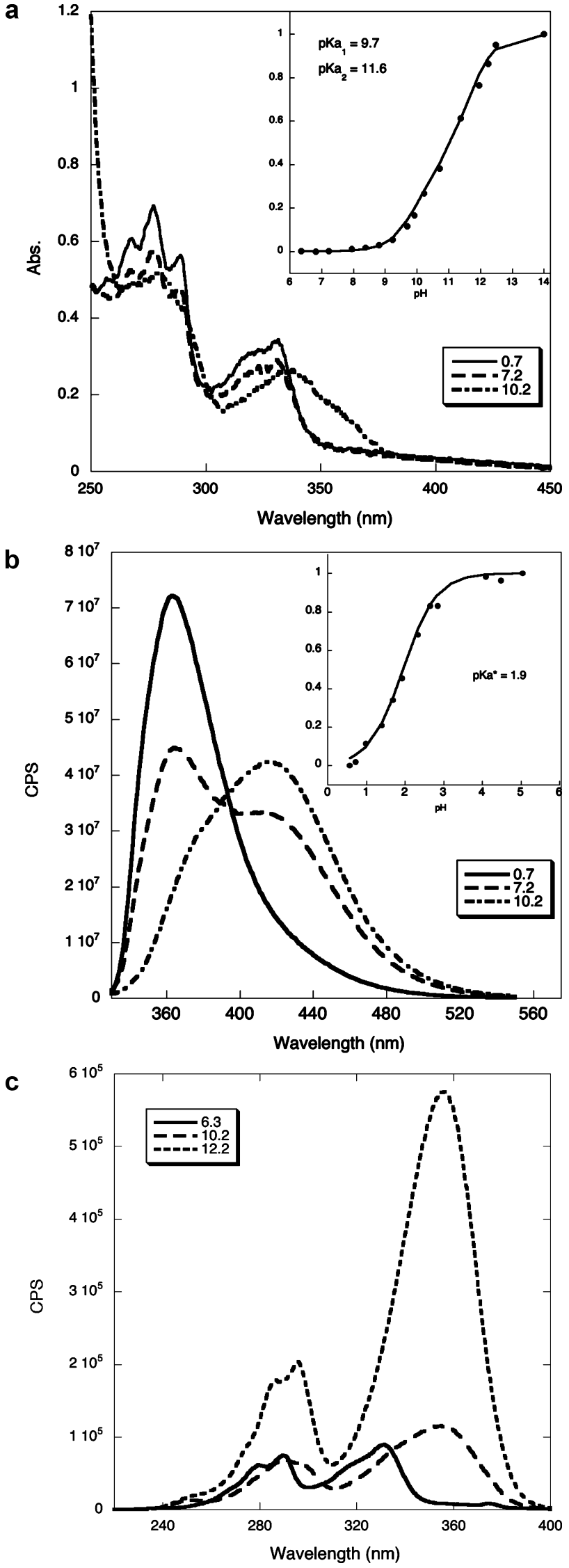

Figure 3. Spectroscopic characterization of $\mathrm{NO} 2 \mathrm{nH}$; (A) Absorption, (B) Fluorescence and $(\mathrm{C})$ fluorescence-excitation spectra at the indicated $\mathrm{pH}$ values in $2 \% \mathrm{MeOH} / \mathrm{H}_{2} \mathrm{O}$. The insets in (A) and (B) report $\mathrm{p} K_{\mathrm{a}}$ and $\mathrm{p} K_{\mathrm{a}}^{*}$ measurements, respectively. 
due to the presence of decay mechanisms in $* \mathrm{ROH}$ that are competitive with proton transfer to the solvent. Following this reasoning, the decrease in fluorescence intensity gives the ${ }^{*} \mathrm{RO}^{-}$ formation quantum yield $\Phi_{*_{\mathrm{RO}}} \approx 0.48$. The carbanion formation quantum yield is then $\Phi_{\mathrm{C}^{-}}=\Phi_{\mathrm{H}^{+}}=\phi_{\mathrm{H}^{+}} \Phi_{*{ }^{\mathrm{RO}}} \approx 0.3$. With such a high quantum yield, even under very mild experimental conditions (laser energy of $3 \mathrm{~mJ} / \mathrm{pulse}$ at $266 \mathrm{~nm}, 5-6 \mathrm{~ns}$ laser pulse width, photoacid absorbance $\mathrm{A}_{266}=0.4$, irradiated volume of $0.1 \mathrm{~mL}$ ) an aqueous solution initially at $\mathrm{pH} 7$ should acidify to $\mathrm{pH} 5$ within the laser pulse and return to neutrality in one second.

The predominant species in the $8-11 \mathrm{pH}$ range is a monoanion, with the proton located either in the oxygen atom of the naphthol or in the carbon atom at the $\alpha$ position to the nitro group. Carbanions of nitroalkanes may delocalize part of the charge to the adjacent nitro group and resemble a nitronate anion. ${ }^{32}$ This is an intrinsic property of nitroalkanes and a integral part of their characteristic proton transfer reactions, but only the C-protonation drives the system to its minimum energy and is the reaction coordinate of interest to this work. In view of the calculated intramolecular proton transfer rate and of the similarity between the $\mathrm{p} K_{\mathrm{a}} \mathrm{s}$ of naphthol and 2-phenyl-1nitroethane, both the naphtholate and the carbanion forms are present in equilibrium in the ground state. The absorption spectra at $\mathrm{pH} 10.2$ and 11.9 reflect the change from a mono to a dianion, but do not inform on the spectral properties on the two monoanions. Fluorescence excitation spectra of Figure 3C suggest that the band near $350 \mathrm{~nm}$ corresponds to the naphtholate form of the anion.

Other mechanisms may be invoked for the quenching of $* \mathrm{RO}^{-}$fluorescence in $\mathrm{NO} 2 \mathrm{nH}$. However, we can exclude solvation effects, because the presence of hydroxyl groups in the alkyl chain increases the intensity of the anion emission, ${ }^{25}$ whereas we observe a decrease in fluorescence intensity in the presence of the nitro group. The fluorescence decays obtained at the emission maxima of $* \mathrm{ROH}(360 \mathrm{~nm})$ and $* \mathrm{RO}^{-}(430$ $\mathrm{nm}$ ), measured by single-photon counting and shown in Figure 4 , are not amenable to a simple interpretation because geminate recombination leads to nonexponential behavior. ${ }^{33}$ Nevertheless, the decay of $* \mathrm{RO}^{-}$gives a good fit to an exponential decay with a time constant $k_{* \text { RO- }}=1.4 \times 10^{8} \mathrm{~s}^{-1}$ which, after subtraction of the decay constant measured for the anion of 1-propyl-2-naphthol, ${ }^{25}$ gives $k_{\text {ipt }} \approx 10^{8} \mathrm{~s}^{-1}$ in $2 \% \mathrm{MeOH}: \mathrm{H}_{2} \mathrm{O}$. This is in excellent agreement with the rate constant $k_{\text {ipt }}=2.6$ $\times 10^{8} \mathrm{~s}^{-1}$ anticipated with ISM.

Direct evidence for the formation of a long-lived monoanion upon electronic excitation of $\mathrm{NO} 2 \mathrm{nH}$, is presented in Figure 5. Excitation at $266 \mathrm{~nm}$ of $0.1 \mathrm{mM}$ of $\mathrm{NO} 2 \mathrm{nH}$ in $2 \% \mathrm{MeOH} / \mathrm{H}_{2} \mathrm{O}$ initially at $\mathrm{pH} 7$ produces a transient absorption spectrum with bands at 315 and $355 \mathrm{~nm}$ with similar decays. The spectra were collected at sufficiently long times to ensure that any naphtholate formed directly from its excited state is already reprotonated back to the neutral form of $\mathrm{NO} 2 \mathrm{nH}$. Considering that the rate of formation of the naphtholate from the carbanion is much slower than the rate of protonation of the naphtholate, we assign the spectra in Figure 5A to the carbanion. The reestablishment of Equilibrium (5) is characterized by a relaxation time, defined as the time at which the distance from equilibrium is $1 / e$ of the initial distance. The relaxation time can be extracted from the

(32) Erden, I.; Keefe, J. R.; Xu, F.-P.; Zheng, J.-B. J. Am. Chem. Soc. 1993, 115, 9834-9835.

(33) Agmon, N.; Huppert, D.; Masad, A.; Pines, E. J. Phys. Chem. 1991 95, 10407-10413.

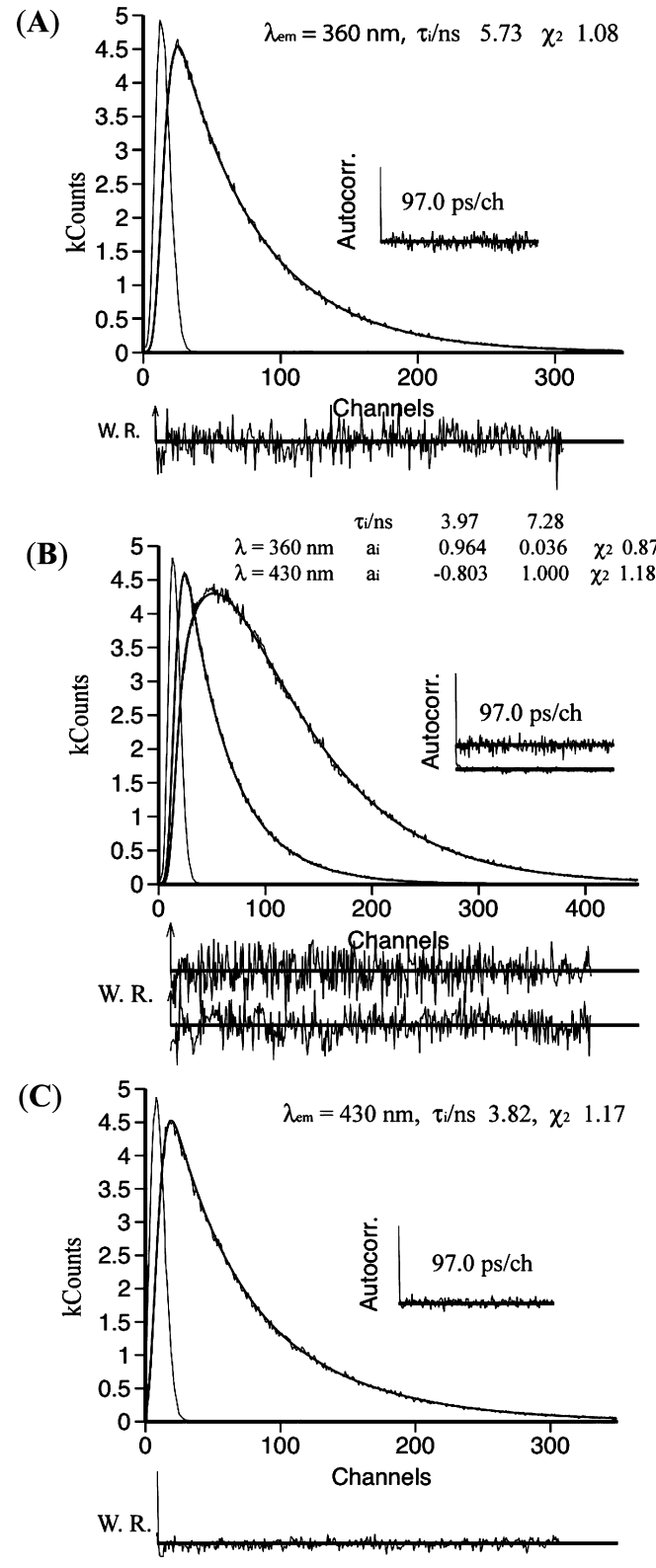

Figure 4. Single photon counting of 1-(2-nitroethyl)-2-naphthol. (a) At $\mathrm{pH}$ 1.0. (B) At $\mathrm{pH}$ 6.4. (C) $\mathrm{pH} 12.2$.

experimental data as shown in Figure 5B. The value obtained, $\tau \approx 0.6 \mathrm{~s}$, is in remarkable agreement with the relaxation time predicted by theoretical modeling of this system, $1 \mathrm{~s}$. We can classify this $\mathrm{pH}$ jump as "persistent" in the perspective of all the processes that occur in millisecond and submillisecond regimes and that cannot be studied by rapid-mixing techniques.

Definitive evidence for the mechanism of Figure 1 can be obtained with photolysis in $2 \% \mathrm{MeOD} / \mathrm{D}_{2} \mathrm{O}$, which must lead to the incorporation of deuterium in $\mathrm{NO} 2 \mathrm{nH}$. The inset in Figure 2A shows the NMR spectra of $\mathrm{NO} 2 \mathrm{nH}$ collected before and after $1 \mathrm{~min}$ photolysis in $2 \% \mathrm{MeOD} / \mathrm{D}_{2} \mathrm{O}$ with a mercury lamp at $254 \mathrm{~nm}$. The compound was extracted with $\mathrm{CDCl}_{3}$ and the NMR spectra were registered in this solvent. The triplet assigned to the protons next to the nitro group decreases in intensity, as expected from the protonation of the carbanion by $\mathrm{D}_{3} \mathrm{O}^{+}$. At the same time, the benzylic protons become a doublet because the coupling is now with only one proton. Potassium ferrioxalate actinometry reveals that $9 \times 10^{-5}$ moles of photons were absorbed and $9 \times 10^{-7}$ moles of photoacid were present. The 

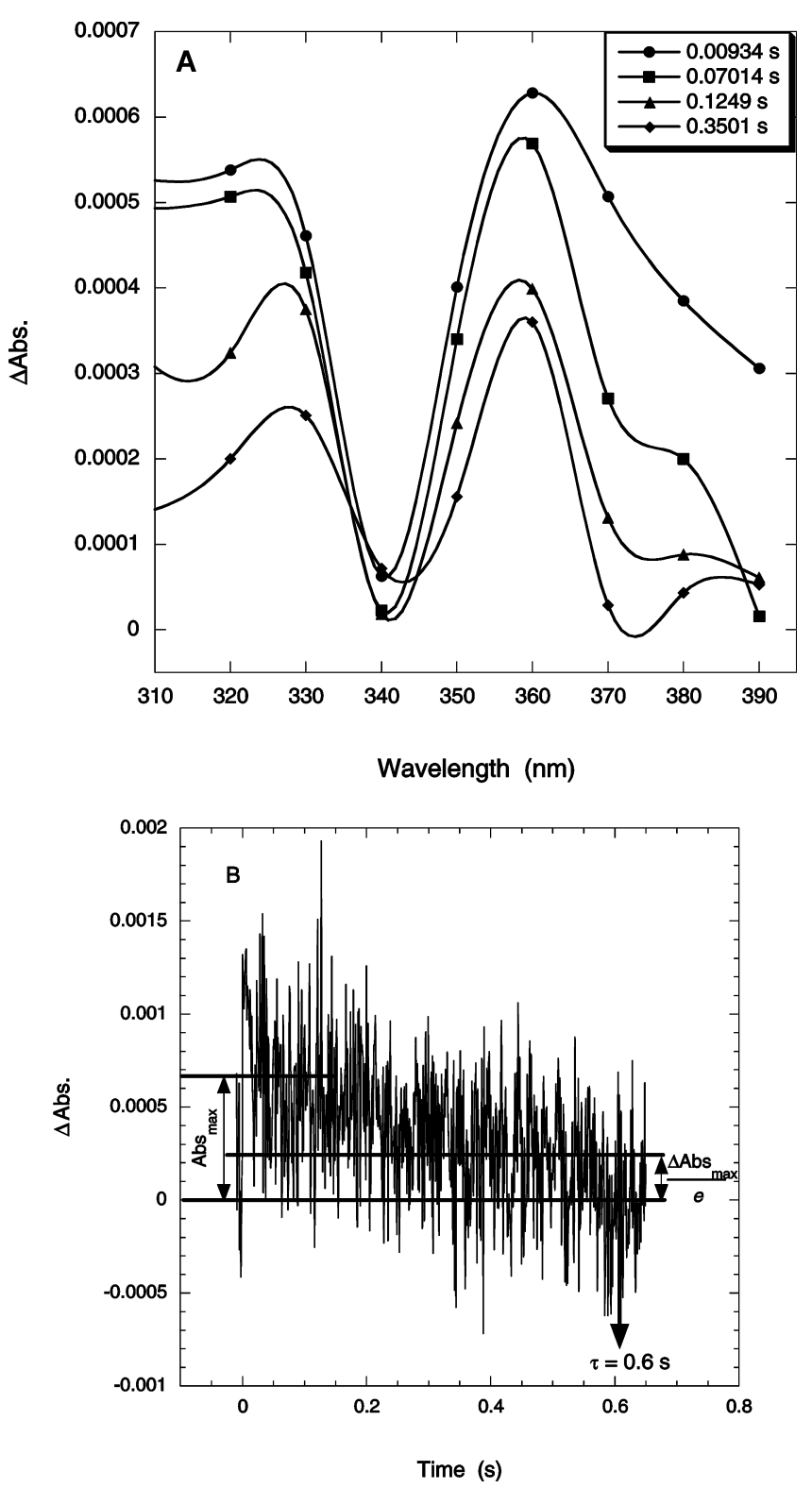

Figure 5. Flash photolysis of $[\mathrm{NO} 2 \mathrm{nH}]=4.3 \times 10^{-4} \mathrm{M}$ in $2 \% \mathrm{MeOH}$ : $\mathrm{H}_{2} \mathrm{O}$. (A) Transient absorption spectra. (B) Decay at $360 \mathrm{~nm}$.

excess of protons released should lead to $100 \%$ deuteration of $\mathrm{NO} 2 \mathrm{nH}$. The NMR spectra show that this extensive deuteration is not accompanied by significant degradation. Moreover, detailed analysis of the aromatic region of the NMR spectra reveals that incorporation of deuterium in the $\alpha$ position of the nitro group is not accompanied by changes in the aromatic protons. Thus, we conclude that our persistent photoacid is also reversible.

The data above proves the success of the design of persistent and reversible photoacids that employ competitive intramolecular proton transfer from a carbon acid. The amplitude of the $\mathrm{pH}$ jump in such systems is limited by the acidity of the photoacid $\left(\mathrm{p} K_{\mathrm{a}}^{*}=1.5\right.$ from fluorescence titration), by its solubility and by the intensity of the laser pulse. The color change of $\mathrm{pH}$ indicators is a very convenient tool to assess the amplitude of the $\mathrm{pH}$ jump and the availability of the excess protons to participate in chemical reactions. We employed bromocresol green $\left(\mathrm{p} K_{\mathrm{a}}=4.9\right)$ and observed the bleaching and recovery of its basic form $\left(\mathrm{In}^{2-}\right)$ at $616 \mathrm{~nm}$, where the absorption
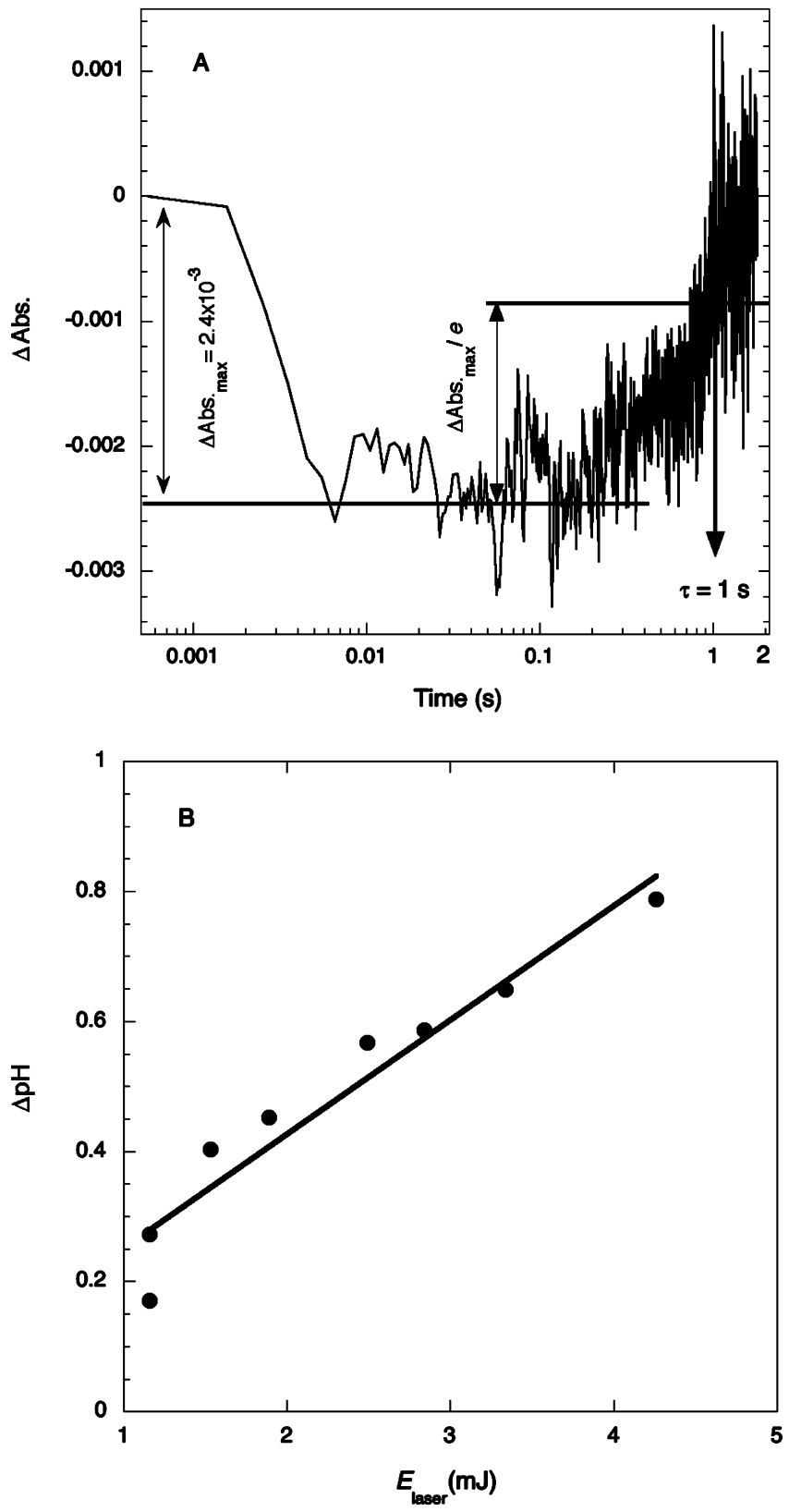

Figure 6. Transient bromocresol green absorption at $616 \mathrm{~nm}$ following flash photolysis of $[\mathrm{NO} 2 \mathrm{nH}]=2 \times 10^{-4} \mathrm{M}$ in $2 \% \mathrm{MeOH} / \mathrm{H}_{2} \mathrm{O}$. (A) Bleaching and recovery of bromocresol green absorption with estimate of the relaxation time $\tau$. (B) Dependence of the maximum photobleaching of bromocresol green on the laser intensity; the slight offset of the laser energy is probably due to some $355 \mathrm{~nm}$ stray light reaching the energy meter. No photobleaching is observed in the absence of $\mathrm{NO} 2 \mathrm{nH}$.

coefficient is $\epsilon_{616}=39550 \mathrm{M}^{-1} \mathrm{~s}^{-1}$. Figure $6 \mathrm{~A}$ shows that the absorbance change produced by a $3 \mathrm{~mJ}$ laser pulse $2 \mathrm{~mm}$ in diameter in a $2 \% \mathrm{MeOH} / \mathrm{H}_{2} \mathrm{O}$ solution with initial indicator concentration $\left[\mathrm{In}^{2-}\right]=9.1 \times 10^{-6} \mathrm{M}$ at pH 7, is $\Delta \mathrm{A}_{616}=-2.4$ $\times 10^{-3}$. This absorbance change corresponds to $\Delta\left[\mathrm{In}^{2-}\right]=3 \times$ $10^{-7} \mathrm{M}$ and a jump to $\mathrm{pH}$ 6.3. This is a conservative estimate given the geometric mismatch between the analyzing light beam and the laser flash. A more realistic estimate is that the lowest $\mathrm{pH}$ attained with this $3 \mathrm{~mJ}$ laser pulse is between the theoretical estimate of $\mathrm{pH} 5$ and the experimental evidence for $\mathrm{pH}$ 6. More importantly, as shown in Figure 6B, is that the magnitude of the $\mathrm{pH}$ jump is directly proportional to the laser energy. With 


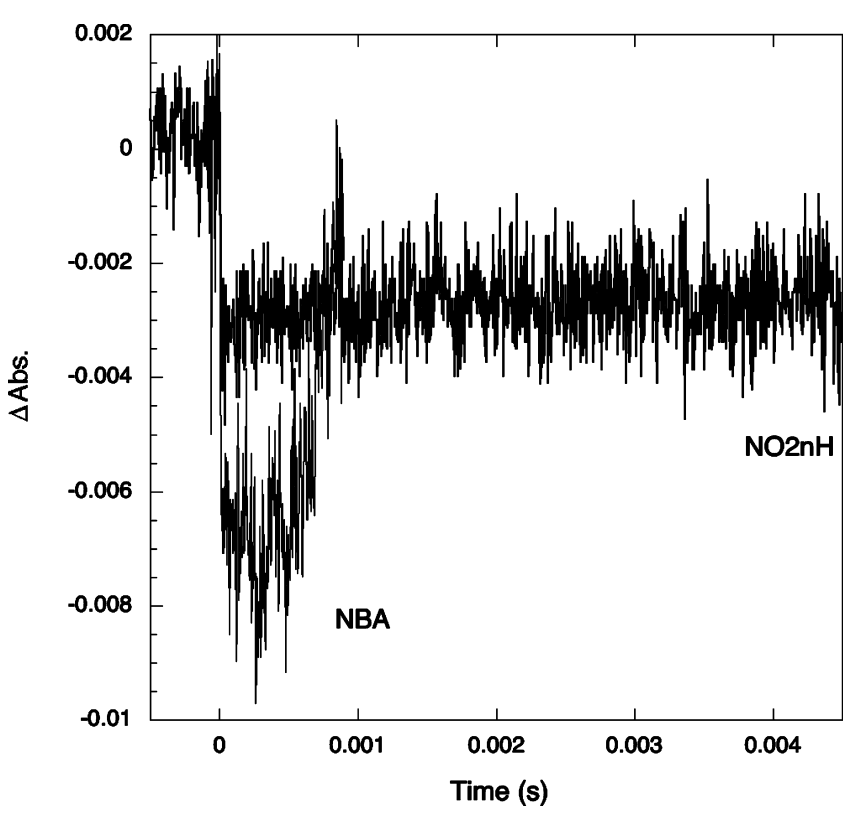

Figure 7. Transient bleaching of bromocresol green absorption at $616 \mathrm{~nm}$ following flash photolysis of $[\mathrm{NO} 2 \mathrm{nH}]=2 \times 10^{-4} \mathrm{M}$ or of $[\mathrm{NBA}]=4 \times$ $10^{-3} \mathrm{M}$ in $2 \% \mathrm{MeOH}: \mathrm{H}_{2} \mathrm{O}$. The initial $\mathrm{pH}$ was 5.2 and the indicator concentration was $1.2 \times 10^{-5} \mathrm{M}$ for $\mathrm{NO} 2 \mathrm{nH}$ and $2.5 \times 10^{-6} \mathrm{M}$ for NBA experiments.

intense laser pulses, the proton concentration should approach the solubility limit of $\mathrm{NO} 2 \mathrm{nH}$.

The acid-base recombination rate constant of bromocresol green is $k_{\mathrm{on}}=5.8 \times 10^{10} \mathrm{M}^{-1} \mathrm{~s}^{-1},{ }^{34}$

$$
\mathrm{H}^{+}+\mathrm{In}^{2-} \rightleftharpoons \mathrm{HIn}^{-}
$$

and the ionization rate constant is $k_{\text {off }}=6.8 \times 10^{5} \mathrm{~s}^{-1}$. Both these rates are much faster than the corresponding ones for Equilibrium (5), which means that the acid and basic forms of bromocresol green are in equilibrium at the medium $\mathrm{pH}$ all along the recovery of the system to neutrality. Thus, the ratedetermining factor for the recovery of bromocresol green is the bimolecular reprotonation of the carbanion, and the relaxation time of $\left[\mathrm{In}^{2-}\right]$ should be the same as that of the carbanion. Figure 6A shows that the relaxation time of bromocresol green is $\tau=$ $1 \mathrm{~s}$, which is the same within experimental error as that of the carbanion in Figure 5B. This experiment shows that the protons generated in the irradiated volume establish new equilibria in the submillisecond time scale and that $\mathrm{pH}$-dependent equilibrium concentrations in that regime can be followed directly.

The breakthrough in the $\mathrm{pH}$ jump technique made possible by $\mathrm{NO} 2 \mathrm{nH}$ can be best appreciated comparing its persistent and reversible $\mathrm{pH}$ jump with the $\mathrm{pH}$ jump produced by the most common caged proton compound, $o$-nitrobenzaldehyde (NBA), ${ }^{35}$ under similar conditions, Figure 7. NBA is capable

(34) Warrick Jr., P.; Auborn, J. J.; Eyring, E. M. J. Phys. Chem. 1972, 76, 1184-1191. of $\mathrm{pH}$ jumps lasting for seconds when the initial $\mathrm{pH}$ is close to 7. However, in our experiments with $\mathrm{pH} 5.2$, adjusted with $\mathrm{HCl}$, the $\mathrm{pH}$ jump produced with NBA is quenched in milliseconds presumably as a result of reactions of the NBA product. Terazima observed a similar effect and concluded that experimental results utilizing caged compounds must be carefully analyzed in view of the possible reactions of NBA photoproducts, namely with $\mathrm{Cl}^{-36}$

\section{Conclusions}

The design and synthesis of a persistent and reversible photoacid was motivated by theoretical modeling, and is another illustration of scientific advances driven by theory. The synthesis of 1-(2-nitroethyl)-2-naphthol was achieved by a simple two step procedure, that allows the isolation of the desired product without requiring chromatographic separations and is a valid starting point for scale-up procedures.

In aqueous solutions, deprotonation of 1-(2-nitroethtyl)-2naphthol is essentially completed in $10 \mathrm{~ns}$, and leads to a carbanion located at the $\alpha$ position to the nitro group with a ca. $30 \%$ efficiency. The relaxation time for the reprotonation of this carbanion, and the consequent return to neutrality, is close to $1 \mathrm{~s}$. Thus, from $10 \mathrm{~ns}$ to $0.1 \mathrm{~s}$, the irradiated volume remains acidic and at a nearly constant $\mathrm{pH}$. This offers a simple method to study $\mathrm{pH}$-dependent processes that are faster than the time resolution of rapid-mixing techniques.

The flash photolysis data was collected as an average of 5 laser pulses with laser repetition rates below $0.2 \mathrm{~Hz}$. Each laser shot produces a similar transient spectrum, and the baseline fully recovers before the next shot. The $\mathrm{pH}$ jumps corresponding to the on-off light cycles are highly reproducible. Pure samples can be subject to hundreds of laser pulses without appreciable spectral changes. $\mathrm{NO} 2 \mathrm{nH}$ is the first example of a persistent and reversible photoacid and proves the feasibility of this concept.

Finally, it must be emphasized that these photoacids offer a local control of acidity and that while diffusing a few micrometers from the irradiated volume, the carbanion is neutralized.

Acknowledgment. This work was supported by FCT and FEDER (project no. POCI/QUI/55505/2004). R.M.D.N. thanks FCT for the grant SFRH/BD/24005/2005. We thank the Nuclear Magnetic Resonance Laboratory of the Coimbra Chemistry Centre for obtaining the NMR data.

Supporting Information Available: ${ }^{1} \mathrm{H}$ NMR and ${ }^{13} \mathrm{C}$ NMR. Input and output files for ISM calculations through the Internet, together with the explanation of the terms employed. This material is available free of charge via the Internet at http:// pubs.acs.org.

\section{JA901930C}

(35) Viappiani, C.; Bonetti, G.; Carcelli, M.; Ferrari, F.; Sternieri, A. Rev. Sci. Instrum. 1998, 69, 270-276.

(36) Choi, J.; Terazima, M. J. Phys. Chem. B 2003, 107, 9552-9557. 